\title{
Perspective
}

\section{Health and Wellness Policy Ethics}

\author{
Frank J. Cavico, Bahaudin G. Mujtaba ${ }^{*}$
}

The H. Wayne Huizenga School of Business and Entrepreneurship, Nova Southeastern University, Ft. Lauderdale, Florida, USA

Received: 17 July 2013, Accepted: 2 August 2013, ePublished: 3 August 2013

\begin{abstract}
This perspective is an ethical brief overview and examination of "wellness" policies in the modern workplace using practical examples and a general application of utilitarianism. Many employers are implementing policies that provide incentives to employees who lead a "healthy" lifestyle. The authors address how these policies could adversely affect "non-healthy" employees. There are a wide variety of ethical issues that impact wellness policies and practices in the workplace. The authors conclude that wellness programs can be ethical, while also providing a general reflective analysis of healthcare challenges in order to reflect on the externalities associated with such policies in the workplace.
\end{abstract}

Keywords

Wellness Policies, Healthy Employees, Discrimination, Ethics, Utilitarianism

\section{Background}

Many employers today are very concerned about the increase in healthcare costs. Accordingly, employers want healthy employees in order to avoid absences, enhance productivity, and improve morale. So employers are looking for ways to reduce healthcare costs and to enhance the overall health of their employees. One beneficial measure is in the form of "wellness" programs in the workplace, which encourage or at times attempt to "force" employees to lose weight, stop smoking, reduce health risks, and overall improve their health. However, employers have to be very careful in creating and implementing wellness programs since there are a variety of ethical challenges that can apply to wellness policies. The purpose of this perspective is to provide a brief reflection on the ethical challenges associated with healthcare in the modern workplace so human resources professionals and their employers can consider all sides of their policies prior to implementation.

Most employers prefer the "carrot" approach because it does not alienate employees due to their chronic health conditions (1). Nevertheless, some question if even the "carrot" approach was a truly voluntary one (2). If the "carrot" approach does not work, and employees cannot, or will not, "voluntarily" become or stay healthy, and consequently employers continue to see healthcare costs rise, employers may consider "forcing" employees to be healthy by penalizing unhealthy employees. A recent survey indicated that $60 \%$ of the employers stated that they plan to impose penalties in the next three to five years on workers who do not improve their health (3). Kwoh predicted a "murky" future-legally, ethically, and practically-for these increasing, and increasingly punitive, "stick" wellness programs (4).

There are many critics, however, of a punitive "stick" approach to wellness in the workplace. Sizemore fears that "the potential for discrimination and harassment at the workplace for failure to participate in the program also exists" (2). There is also a fear that these wellness programs-whether voluntary or mandatory -are giving employers too much control over their employees' lives (4). Kwoh reported on another critic of wellness programs who condemned wellness programs as "unethical" because the employer's main motivation is not to improve the employees' health but to get smokers and other employees with "unhealthy" lifestyles "off their health bill and pass on the costs to someone else." A professor of public health, called wellness policies a "slippery slope", and expressed concern about what employee actions would be penalized next, such as going out for fastfood (3). Critics assert that wellness programs, even incentivebased ones, are unfair because they can disadvantage some people most in need of healthcare and also that they, in effect, penalize employees who legitimately struggle to attain wellness objectives, but who fail or who regress, particularly since it is recognized that major lifestyle changes are difficult to achieve (5).

\section{Ethical considerations}

The subject of wellness-based employer decision-making raises very controversial and important moral issues. Is it moral based on ethics for employers to adopt wellness programs? Determining whether an action, rule, or law is moral or immoral, right or wrong, or just or unjust perforce brings one into the realm of ethics. In this perspective, we can certainly apply the utilitarianism ethical theory to the subject of wellness-based employer decision-making to determine if such discrimination in employment is moral.

Utilitarianism is a major ethical theory in Western civilization; it was created principally by the English philosophers and social reformers Jeremy Bentham and John Stuart Mill $(6,7)$. Utilitarianism is regarded as a consequentialist perspective,

*Corresponding author: Bahaudin G. Mujtaba; Email: mujtaba@nova.edu 
also called a teleological ethical theory; that is, one determines morality by examining the consequences of an action. If an action produces more good than bad consequences, it is a moral action; and if an action produces more bad than good consequences it is an immoral action. After determining the action to be evaluated, the next step in the utilitarian analysis is to determine the people and groups, that is, the stakeholders, affected by the action.

There are a variety of stakeholders, or constituent groups, that are affected by wellness policies in the workplace. The most directly affected stakeholder group is the employees. Despite the good goals of these wellness programs, there are moral issues which arise and which directly impact employees-both positively and negatively. There certainly will be positive consequences if the wellness program operates as a benefit for employees and especially so if the employer provides material benefits for participation. Employees naturally will benefit from becoming and staying healthy - and not just physically, but emotionally too. Being healthy and fit will supply one with more energy as well as relieve stress and anxiety. They will be able to perform their jobs more efficiently and engage in better interpersonal relations, which is not only beneficial to the employers, but also the employer too. An incentive-based wellness program should improve office morale and instill in the employees a deeper sense of job satisfaction. Another benefit to employees, as well as their families, would be if a wellness program causes an early identification of a medical problem, thereby alerting an employee to seek early medical care. For example, the obesity rate in the U.S. is very high and thus it should be construed as a positive benefit for employers to encourage obese employees to lose weight.

On the negative side, employers using the "stick" approach to wellness programs in the workplace may produce some negative feelings on the part of employees, such as the employer being invasive, intrusive, and paternalistic. Employees who are obese, or smoke, or who are chronically diseased, or engage in unhealthy behaviours may feel penalized, even by an incentivebased program, and thus feel pain. All employees, moreover, would be concerned that their private and personal health information could be made public and misused, resulting in embarrassment or discrimination. Even an initial health assessment could reveal medical information that an employee might wish to keep private. Further negative consequences could arise if the employee is a single mother who is "pressed for time" and thus who cannot go to her employer's gym and exercise classes in order to lower her premiums. Yet one could argue that even "forcing" the employee to take some responsibility for his or her own health and "make" them work on achieving a healthy lifestyle will be good for the employee in the long-term.

Families of employees certainly want their "loved-ones" as well as "bread-winners" to be healthy and not become sick or die prematurely. They certainly will be pleased by the increase in take-home pay due to an incentive-based program with reduced employee insurance costs. Moreover, the now healthier employee may serve as a role model for his or her family members, who also may be encouraged to participate in wellness programs; and thus the whole family will be healthier and, presumably, happier. Job applicants who are healthy will certainly be attracted to a company with an incentive-based wellness program since they will have more "take-home" pay. They may feel positive about going to work for an employer who is so health-conscious and concerned. However, some job applicants might be negatively affected if they are fearful of healthcare testing because they are reticent about disclosing medical issues, or they are struggling with their weight or smoking habits, and thus they may not seek or pursue employment. Yet perhaps the existence of such a program will motivate an "unhealthy" job applicant to get healthy to obtain employment and then participate in the benefits of a company's wellness program.

Employers, of course, are directly affected by wellness programs. Encouraging and even "forcing" employees to become and stay healthy will have positive consequences for the employer, so long as all applicable laws and regulations are complied with. Employees will work better and be more productive as well as less absent and the employer's healthcare costs will be reduced. The problems and costs associated with healthcare issues, such as absenteeism, workplace stress, accidents, and increased healthcare costs will be lessened. Effectiveness, loyalty, and productivity would increase, and health insurance costs would decrease, resulting in an overall increase in profitability, thereby benefitting owners and shareholders.

There may be negative consequences for the employer, however. There will be the costs of setting up and implementing a wellness program, as well as a loss of productive work time, at least in the short-run, as employees attend health seminars and undergo medical testing. Legal issue, naturally, would have to be considered; and thus the employer would have to seek out legal counsel to make sure that its wellness plan is in conformity with the law. If there are legal problems, not only will legal costs ensue, but adverse publicity could result too. If a wellness program is not implemented in a careful and prudent manner, the level of trust between employers and employees could be reduced, employee morale could be decreased; and as such perhaps good and valuable employees, who have no interest in participating in the program, and who may actually feel uncomfortable about it, may seek employment elsewhere. The astute employer, therefore, has to avoid or lessen these negative consequences by convincing employees that it will be costly-for them, their families, the employer, and society as a whole for the employees to have an unhealthy lifestyle.

Customers, consumers, and clients could gain some indirect benefits from a workplace wellness program. Doctors, nurses, laboratories, and other healthcare providers and institutions surely would benefit from employment wellness programs as their professional services would be an essential component of such programs. The legal system certainly would be challenged in the effort to apply all the statutory, regulatory, and common laws to wellness program disputes in the workplace. Yet, that is their "job"-to develop the appropriate legal framework and ultimately to do justice!

Any increase in productivity, profits, and pay will inure to the benefit of the local community where the employer is based, especially if the employer is a socially responsible one who contributes to local charities and who is engaged in civic and community affairs. Company growth helps the local tax base and helps to provide jobs-directly by the employer and indirectly for the healthcare professionals and businesses involved in the wellness programs.

Overall, despite some negative consequences, it appears that there are more positive consequences for the stakeholder groups affected by employer wellness programs. Employers implementing wellness programs, particularly if voluntary and incentive-based, would produce more pleasure than pain. Thus, pursuant to the utilitarian ethical theory wellness programs in 
the workplace can be deemed moral. Nevertheless, regardless of any utilitarian moral conclusions based on a perceived "greater good," many academics, practitioners, and civil rights, union, and employee advocacy groups are troubled by a teleological business-oriented approach to wellness policies, standards, and practices in employment. As such, to increase its acceptance and minimize resistance, employers should proactively and comprehensively emphasize the benefits of their wellness programs (be they "carrots" or "sticks") to all relevant stakeholders prior to implementation. Both incentive programs and penalty programs can serve as motivational factors to focus employees on becoming healthier and to reduce the employer's healthcare costs.

\section{Conclusion}

Utilitarianism advocates the implementation of an alternative that maximizes its benefits to the greatest number of individuals who are impacted by it. Obviously, by the nature of utilitarian analysis, a small number of workers may not benefit since the focus is on the achievement of the greatest benefit to the majority. Human resources and legal experts in the company should review those who are in the minority to make sure they are not part of any protected group since unintentional discrimination as well as any adverse or disparate impact based gender, disability, age, ethnicity, or even pregnancy, for example, are illegal in the United States. As such, when possible, the authors recommend that human resources professionals and their employers look closely at those alternatives that benefit all workers and other relevant stakeholders in order to create winwin outcomes for everyone.

The focus of this brief perspective was not to provide new knowledge or to extend knowledge in this field, but rather to provide a reflection on the ethical challenges associated with health policies in the modern workplace so human resources professionals can consider all sides of their policies prior to implementation. Another reason for this reflective perspective is to clarify the dilemmas on health policies so future researchers can conduct scientific studies on it. Despite the usual limitations for any short paper, the authors have provided an overview of wellness programs and policies in the United States. Those who are interested in conducting scientific research can benefit from many studies by active researchers in this field as well as our more comprehensive articles on the subject.

Despite the challenges presented here and those mentioned by other researchers, creating and implementing a wellness program can be very beneficial to the employer as well as the employee. Doing nothing is not a good option since healthy employees are likely to be more productive employees. The key is to initiate a well-intentioned program and then keep on improving it to make sure everyone benefits from it. The goal, as always, is to act legally and ethically when implementing health policies.

The employer's ultimate objective, therefore, should be to create a "wellness culture" in the workplace by means of its legal and moral wellness program and other healthy-lifestyle measures. A moral wellness program is a socially responsible and mutually beneficial action for everyone involved.

\section{Acknowledgments}

We are working with our colleagues, Stephen C. Muffler and Marissa Samuels at NSU, to develop more comprehensive articles on the legal issues and ethical analysis of wellness programs in the United States.

\section{Ethical issues}

There are no ethical issues for this perspective paper.

\section{Competing interests}

The authors declare that there are no competing interests.

Authors' contributions

FJC initiated the study and both authors jointly developed this perspective.

References

1. Mujtaba BG, Cavico FJ. A Review of Employee Health and Wellness Programs in the United States. Public Policy and Administration Research 2013; 3: 1-15.

2. Sizemore SC. A Fatter Butt Equals a Skinnier Wallet: Why Workplace Wellness Programs Discriminate Against the Obese and Violate Federal Employment Law. Wyoming Law Review 2011; 11: 639-72.

3. Santich Kate. The price of poor health. Sun-Sentinel 2013, April 28: 4D.

4. Kwoh L. Shape Up or Pay Up: Firms Put in New Health Penalties. Wall St J 2013, April 6-7: A1-10.

5. Schmidt H, Voigt K, Wikler D. Carrots, sticks, and health care reform-problems with wellness incentives. N Engl J Med 2010; 362: e3.

6. Cavico FJ, Mujtaba BG. Business Ethics: The Moral Foundation of Effective Leadership, Management, and Entrepreneurship. Boston: Pearson; 2009.

7. Cavico FJ, Mujtaba BG. Legal Challenges for the Global Manager and Entrepreneur. lowa: Kendall-Hunt; 2008. 